\title{
Acid-base Balance in Acute Gastrointestinal Bleeding*
}

\author{
T. C. NORTHFIELD, B. J. KIRBY, ANNE E. TATTERSFIELD
}

British Medical fournal, 1971, 2, 242-244

\section{Summary}

Acid-base balance has been studied in 21 patients with acute upper gastrointestinal bleeding. A low plasma bicarbonate concentration was found in nine patients, accompanied in each case by a base deficit of more than $3 \mathrm{mEq} /$ litre, indicating a metabolic acidosis. Three patients had a low blood $\mathrm{pH}$. Hyperlactataemia appeared to be a major cause of the acidosis. This was not accompanied by a raised blood pyruvate concentration. The hyperlactataemia could not be accounted for on the basis of hyperventilation, intravenous infusion of dextrose, or arterial hypoxaemia. Before blood transfusion it was most pronounced in patients who were clinically shocked, suggesting that it may have resulted from poor tissue perfusion and anaerobic glycolysis. Blood transfusion resulted in a rise in lactate concentration in seven patients who were not clinically shocked, and failed to reverse a severe uncompensated acidosis in a patient who was clinically shocked. These effects of blood transfusion are probably due to the fact that red blood cells in stored bank blood, with added acid-citratedextrose solution, metabolize the dextrose anaerobically to lactic acid. Monitoring of acid-base balance is recommended in patients with acute gastrointestinal bleeding who are clinically shocked. A metabolic acidosis can then be corrected with intravenous sodium bicarbonate.

\section{Introduction}

It has long been recognized that a metabolic acidosis may accompany traumatic shock (Cannon, 1918; Cournand et al., 1943). This was first described in battle casualties during the first World War. A metabolic acidosis has also been shown to accompany shock of purely haemorrhagic origin induced experimentally in dogs (Root et al., 1947). Despite these findings, and the clinical observation that a severe haematemesis may be followed by "air hunger" (Deller, 1948), acid-base balance has been little studied in acute gastrointestinal bleeding, though some clinical studies of lactic acidosis have included isolated cases of shock due to gastrointestinal bleeding (Davidson et al., 1946; Huckabee, 1961; Peretz et al., 1964).

\section{Patients and Methods}

Acid-base balance was studied in 21 patients $(17$ men and 4 women) with acute upper gastrointestinal bleeding. Their ages ranged from 20 to 85 (mean 55) years. Eleven had a chronic duodenal ulcer (accompanied by a chronic gastric ulcer in one patient), two had an acute gastric ulcer, one a stomal ulcer,

*This paper is based on part of an M.D. thesis of the University of Cambridge, submitted by T.C.N.

Central Middlesex Hospital, London N.W.10

T. C. NORTHFIELD, M.D., M.R.C.P., Registrar, Department of Gastroenterology (Present address: Guy's Hospital, London S.E.1)

B. J. KIRBY, M.R.C.P., Registrar, Cardiothoracic Department (Present address: Department of Medicine, Royal Infirmary, Edinburgh EH3 9YW) ANNE E. TATTERSFIELD, M.D., M.R.C.P., Registrar, Cardiothoracic Department (Present address: Department of Medicine, Hammersmith Hospital, London W12 0HS) one a probable Mallory-Weiss lesion, one a small-bowel reticulosis, and one had thrombocytopenia. In four patients the cause of bleeding was not identified. Arterial blood samples were taken within 36 hours of hospital admission, with the patients breathing air. No patient received any drugs known to cause a lactic acidosis. Though patients were supine at rest when the blood samples were taken, conditions were not truly basal, as some of them were anxious and not all were fasting. In 14 patients an arterial blood sample was taken before blood transfusion, and in seven the first sample was taken during blood transfusion.

The blood samples were analysed immediately for $\mathrm{pH}$, carbon dioxide tension (PCO.), and oxygen tension ( $\mathrm{Po}_{3}$ ) with a Radiometer electrode system at $37^{\circ} \mathrm{C}$. Plasma bicarbonate concentration and base deficit were derived from $\mathrm{pH}$ and $\mathrm{PCO}_{2}$ by use of Siggaard-Andersen's (1963) nomogram. An aliquot of the blood sample was deproteinized at the bedside with icecold perchloric acid. Blood lactate and pyruvate concentrations were measured by means of a lactate dehydrogenase enzyme assay, the reagent kits supplied by Biochemica Test Combination being used as specified by the manufacturers (Boehringer und Soehne, 1967).

For the purpose of this study arterial hypoxaemia has been defined as an arterial oxygen tension of less than $80 \mathrm{~mm} \mathrm{Hg}$, and clinical shock as the presence of cold, sweaty extremities in combination with a systolic blood pressure of less than 100 $\mathrm{mm} \mathrm{Hg}$.

\section{Results}

Values for $\mathrm{pH}, \mathrm{PCO}_{\text {., }}$ and plasma bicarbonatc concentration in the initial blood samples from all 21 patients are shown in Fig. 1. Nine patients had a plasma bicarbonate concentration below $20 \mathrm{mEq} / 1$. and all nine had a base deficit of more than $3 \mathrm{mEq} / \mathrm{l}$. This was accompanied in each case by a $\mathrm{PcO}_{2}$ below

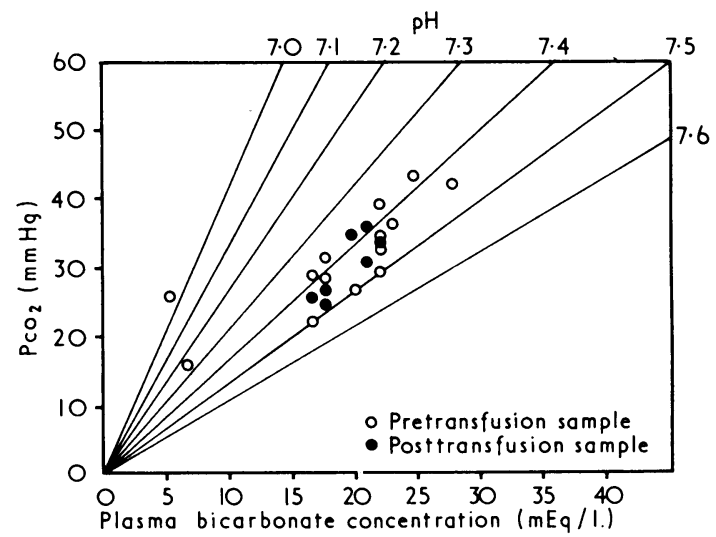

FIG. 1-Artcrial pH, $\mathrm{PCO}_{2}$, and bicarbonate concentration.

$36 \mathrm{~mm} \mathrm{Hg}$. In most cases the $\mathrm{pH}$ remained within normal limits $(7 \cdot 35-7 \cdot 45)$, but in two patients who were severely shocked and semicomatose on admission the $\mathrm{pH}$ was 6.94 and 7.25 in the initial blood sample. A pH of 7.23 was recorded subsequently in a third patient during an episode of severe recurrent haemorrhage. 


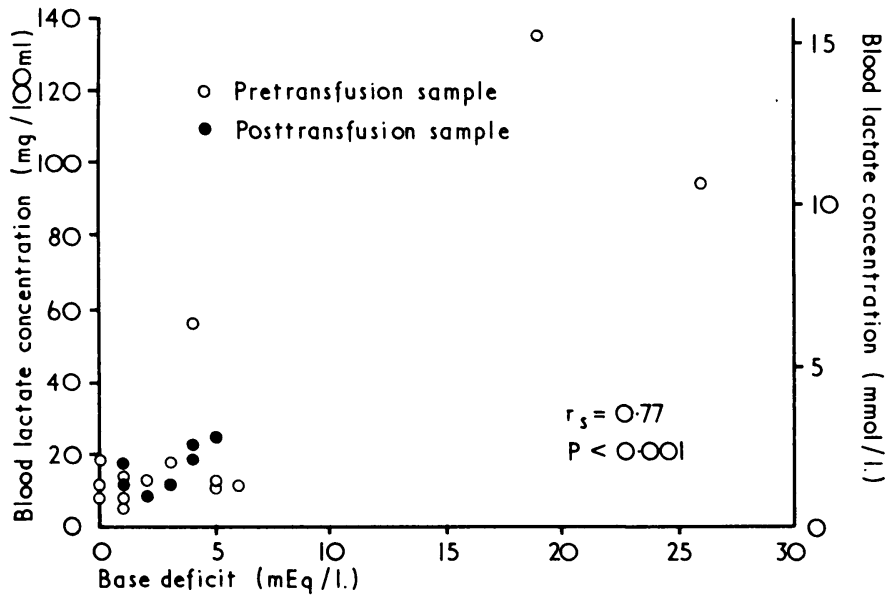

FIG. 2-Correlation between base deficit and blood lactate concentration.

The association between base deficit and blood lactate concentration in the same 21 patients is shown in Fig. 2. All nine patients with a base deficit of more than $3 \mathrm{mEq} / 1$. had a blood lactate concentration of more than $7 \mathrm{mg} / 100 \mathrm{ml}(0.8 \mathrm{mmol} / 1$.$) .$ There was a significant correlation between base deficit and blood lactate concentration (with Spearman's rank correlation test, $\left.r_{s}=0.77 ; P<0.001\right)$. Blood lactate concentration has been expressed in $\mathrm{mmol} / \mathrm{l}$. in addition to $\mathrm{mg} / 100 \mathrm{ml}$ to allow direct comparison with base deficit concentration in $\mathrm{mEq} / \mathrm{l}$. The increase in blood lactate (11 and $15 \mathrm{mmol} / 1$.) would account for much of the acidosis in the two patients with the most severe acidosis (base deficit 26 and $19 \mathrm{mEq} / \mathrm{l}$. respectively).

Blood pyruvate concentration was measured in 12 samples from 10 patients. It was below $1.3 \mathrm{mg} / 100 \mathrm{ml}$ in all 12 , including four having a blood lactate concentration of more than $30 \mathrm{mg} / 100 \mathrm{ml}$. All the samples had a lactate: pyruvate ratio of more than $10: 1$. There was no significant correlation between blood lactate and pyruvate concentration $(r=+0.028)$.

Arterial $\mathrm{Po}_{2}$ was measured in the initial blood sample of 19 patients. Nine patients had arterial hypoxaemia ( $\mathrm{PO}_{2}$ 62-80 $\mathrm{mm} \mathrm{Hg}$, mean value $68 \mathrm{~mm} \mathrm{Hg}$ ). Seven of these had chronic bronchitis, one had bronchopneumonia, and the ninth had no known chest disease but was aged 85 . Ten patients did not have arterial hypoxaemia (Po.. $87-125 \mathrm{~mm} \mathrm{Hg}$, mean value $99 \mathrm{~mm} \mathrm{Hg}$ ). Only two of these had known chest disease. The mean arterial lactate concentration was lower in patients with arterial hypoxaemia $(20 \pm 13 \mathrm{mg} / 100 \mathrm{ml})$ than in those without arterial hypoxaemia $(34 \pm 46 \mathrm{mg} / 100 \mathrm{ml})(0.2<\mathrm{P}<0.5)$.

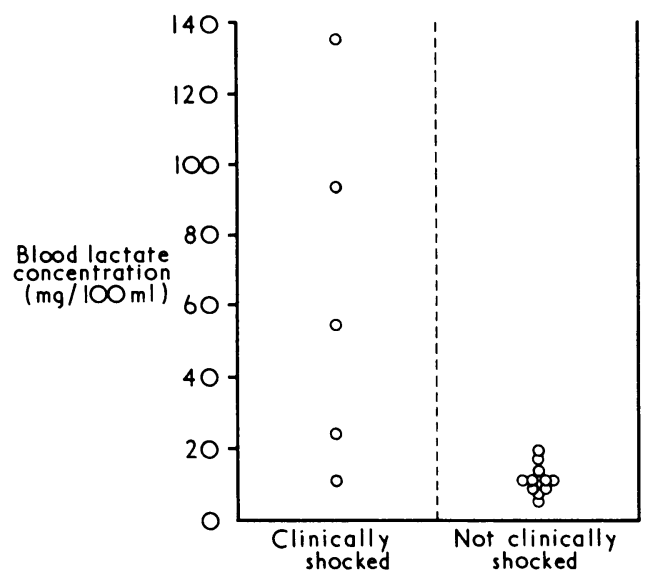

FIG. 3-Relationship between blood lactate concentration and the presence of clinical shock (pretransfusion blood samples only).
The relationship between blood lactate concentration and the presence of clinical shock in patients studied before blood transfusion is shown in Fig. 3. Represented are the 14 untransfused patients shown in Figs. 1 and 2, together with two additional patients on whom acid-base data are not available. The mean blood lactate concentration in those who were clinically shocked was $65 \mathrm{mg} / 100 \mathrm{ml}$ and in those who were not clinically shocked it was $11 \mathrm{mg} / 100 \mathrm{ml}(\mathrm{P}<0.005)$.

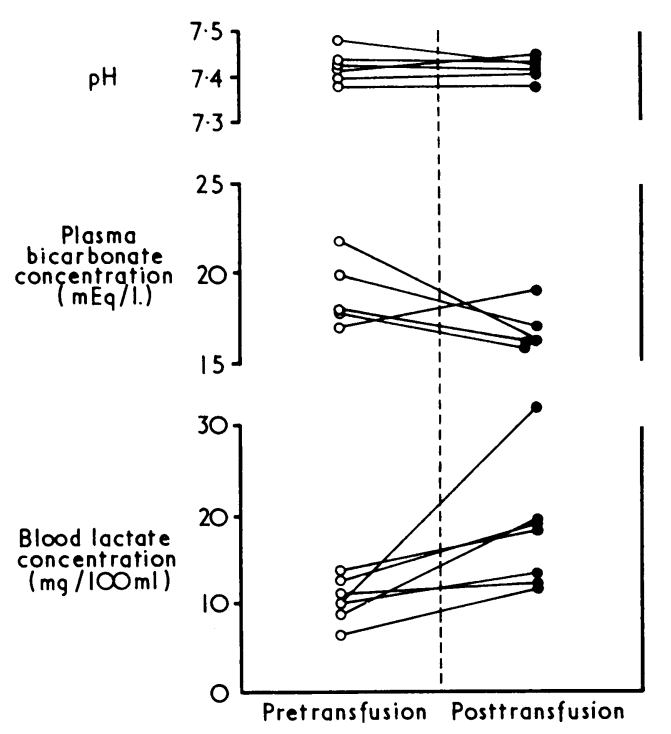

FIG. 4-Effect of blood transfusion.

Several posttransfusion blood samples contained a high blood lactate concentration in the absence of clinical shock. The effect of blood transfusion on blood lactate concentration was therefore studied in seven patients who were not clinically shosked either before or after blood transfusion (Fig. 4). The average volume of blood transfused was $1,250 \mathrm{ml}$ (range $500-2,000 \mathrm{ml}$ ), and the average time interval between the two blood samples was nine hours (range 1-24 hours). The mean lactate concentration rose from 10 to $18 \mathrm{mg} / 100 \mathrm{ml}(P<0.05)$. The mean plasma bicarbonate concentration fell from 19 to 17 $\mathrm{mEq} / \mathrm{l}$. in five patients, but this fall was not significant $(0 \cdot 1 \pm \mathrm{P}<0 \cdot 2)$. The $\mathrm{pH}$ remained within the normal range in all six patients in whom it was measured both before and after transfusion.

The effect of blood transfusion was studied in one patient who had a severe metabolic acidosis in association with clinical shock before blood transfusion. Transfusion of 2 pints $(1,140$ $\mathrm{ml}$ ) of blood in one hour reversed the state of clinical shock, with a rise in blcod pressure from $90 / 60$ to $130 / 70$. There was, however, no real change in acid-base balance; blood $\mathrm{pH}$ rose from $7 \cdot 25$ to $7 \cdot 26$ and plasma bicarbonate concentration from 7 to $8 \mathrm{mEq} / \mathrm{l}$. Blood lactate concentration fell from 137 to $128 \mathrm{mg} / 100 \mathrm{ml}$. In view of the persistence of this severe degree of acidosis the blood $\mathrm{pH}$ was then restored to normal with $200 \mathrm{mEq}$ of intravenous sodium bicarbonate.

\section{Discussion}

Nine of the 21 patients studied had a metabolic acidosis, as indicated by a base deficit of more than $3 \mathrm{mEq} / 1$. This could be largely accounted for by the associated hyperlactataemia. As blood pyruvate concentration was not raised, it is unlikely that the hyperlactataemia was due to either hyperventilation or intravenous dextrose infusion (Huckabee, 1958). It could be explained on the basis of (1) poor tissue perfusion and (2) the effect of blood transfusion. 
There was an association between hyperlactataemia and the presence of clinical shock in patients studied before transfusion. This suggests that the lactic acid has resulted from tissue hypoxia and consequent anaerobic glycolysis. It may, however, be more directly related to high levels of circulating catecholamines, as has been suggested in experimentally induced haemorrhagic shock (Halmagyi et al., 1967). Arterial hypoxaemia cannot have been an important factor in the present study as the lactate concentration tended to be higher in the patients with a normal arterial oxygen tension. Moreover, the mild degree of hypoxaemia in the other patients (62$80 \mathrm{~mm} \mathrm{Hg}$ ) would not, on the basis of experimental work in animals, be expected to cause lactic acidosis, even in the presence of hypocapnia (Takano, 1968).

The results in the present study suggest that blood transfusion itself can cause a rise in blood lactate concentration. This is in accordance with experiments on animals with haemorrhagic shock, where transfusion with bank blood has caused a fall in blood pH (Nahas et al., 1961). An explanation for these observations is provided by the fact that red blood cells in stored bank blood, with added acid-citrate-dextrose (A.C.D.), metabolize the dextrose anaerobically to lactic acid (Gullbring and Ström, 1956; Nahas et al., 1961). It has been found that the lactate concentration exceeds $100 \mathrm{mg} / 100 \mathrm{ml}$ after 10 days' storage (Gullbring and Ström, 1956), and that the $\mathrm{pH}$ falls to 6.2 after three weeks' storage (Nahas et al., 1961). These observations may have therapeutic implications, since acidosis has been implicated (Gain, 1962) as one of the factors contributing to the high incidence of cardiac arrest following massive blood transfusion (Howland et al., 1956; Le Veen et al., 1960; Boyan and Howland, 1963). Infusion of alkali has been shown to decrease the mortality rate following rapid transfusion in the experimental animal (Nahas et al., 1961) and in patients undergoing major surgery (Howland and Schweizer, 1965).

The results in the present investigation suggest that monitoring of acid-base status is advisable in patients with acute gastrointestinal bleeding who are clinically shocked, especially if rapid blood transfusion is contemplated. It is probably unnecessary in patients who are not clinically shocked. A metabolic acidosis is unlikely to be rapidly corrected by blood transfusion alone, but can be corrected with intravenous sodium bicarbonate solution.

We would like to thank Sir Francis Avery Jones and Dr. T. D. Kellock for allowing us to study patients admitted under their care The laboratory in which the estimations were made was supported by the Medical Research Council.

Requests for reprints should be addressed to Dr. T. C. Northfield, Guy's Hospital, London S.E.1.

\section{References}

Boehringer, C. F., und Soehne (1967). Lactate and Pyruvate Determination by UV Method; Biochemica Test Combination, 4th edn. Ingelheim am Rheim.

Boyan, C. P., and Howland, W. S. (1963). fournal of the American Medical Association, 183, 58 .

Cannon, W. B. (1918). Fournal of the American Medical Association, 70, 531. Cournand, A., et al. (1943). Surgery, 13, 964.

Davidson, C.'S., Lewis, J. H., Tagnon, H. J., Adams, M. A., and Taylor, F. H. L. (1946). New England fournal of Medicine, 234, 279

Deller, F. C. (1948). The Modern Management of Gastric and Duodenal Ulcer, p. 66 . Edinburgh, Livingstone.

Gain, E. A. (1962). Canadian Anaesthetists' Society fournal, 29, 207.

Gullbring, B., and Ström, G. (1956). Acta Medica Scandinavica, 155, 413 Halmagyi, D. F. J., Gillett, D. J., and Irving, M. H. (1967). Yournal of Applied Physiology, 22, 487

Howland, W. S., Boyan, C. P., and Schweizer, D. (1956). American fournal of Surgery, 92, 356.

Howland, W. S., and Schweizer, O. (1965). Clinical Anaesthesia, ed. L. R. Orkin, p. 26. Oxford, Blackwell Scientific.

Huckabee, W. E. (1958). Fournal of Clinical Investigation, 37, 244

Huckabee, W. E. (1961). American fournal of Medicine, 30, 833

Le Veen, H. H., et al. (1960). Fournal of the American Medical Association, $173,770$.

Nahas, G. G. Manger, W. M., Mittelman, A., and Ultmann, J. E. (1961) Annals of the New York Academy of Sciences, 92, 596.

Peretz, D. I., McGregor, M., and Dossetor, J. B. (1964). Canadian Medical Association Fournal, 90,673 .

Root, W. S., et al. (1947). American fournal of Physiology, 149, 52. Siggaard-Andersen, O. (1963). Scandinavian fournal of Clinical Laboratory

Takano, N. (1968). Respiration Physiology, 4, 32.

\title{
Gas Exchange in Renal Failure
}

\author{
M. J. GOGGIN, A. M. JOEKES
}

\section{Dangers of Hyperkalaemia during Anaesthesia}

\section{British Medical fournal, 1971, 2, 244-247}

\section{Summary}

Failure to maintain compensatory hyperventilation during anaesthesia in patients with metabolic acidosis results in an increase in $\mathrm{PaCO}_{2}$, fall in blood $\mathrm{pH}$, and a possible rise in plasma potassium. This sequence of events may account for unexplained operative deaths in patients in renal failure.

\section{Institute of Urology, London W.C.2}

M. J. GOGGIN, M.B., M.R.C.P., Lecturer in Nephrology

A. M. JOEKES, M.A., F.R.C.P., Senior Lecturer and Consultant Physician, St. Peter's Group of Hospitals

\section{Introduction}

Renal failure is the commonest background for the presence of a metabolic acidosis. Anaesthesia in patients with metabolic acidosis has long been considered a serious risk, quite independent of the anaemia which is almost invariably present. Fatalities during anaesthesia have not been adequately explained. In some instances hyperkalaemia has been accepted as a cause for cardiac arrest. We have lost several patients undergoing quite minor surgery, such as replacement of an external arteriovenous shunt. In some instances an electrocardiogram immediately before anaesthesia showed no evidence of hyperkalaemia, though the plasma potassium was above the normal range.

All patients with severe renal failure are likely to have respiratory compensation for the metabolic acidosis, with the $\mathrm{PaCO}_{2}$ well below normal. Control of respiration during anaesthesia tends to be based on the known minute volume 